\title{
The influence of interactive and static infographics on the academic achievement of reflective and impulsive students
}

\author{
Dina Ahmed Ismaeel, Ensaf Nasser Al Mulhim \\ King Faisal University
}

\begin{abstract}
This article examines the influence of static/interactive infographics on reflective/impulsive students' academic achievement. The study sample consisted of 80 undergraduate students who were divided into two groups according to their cognitive style (reflective/impulsive). Each group was further divided into two sub-groups based on the type of infographics (static/interactive) to be evaluated. The findings showed that interactive infographics are more effective than static infographics in improving academic achievement. Reflective students outperformed impulsive students in terms of academic achievement, and there was a significant interaction between interactive infographics and reflective students. This study may serve as a guide for educators and designers of learning resources in selecting the most appropriate forms of technology conforming to students' varying cognitive styles.
\end{abstract}

\section{Implications for practice or policy:}

- The designers of e-learning environments must focus on the cognitive style of each learner. The design of those environments must take into account the diversity of information presentation methods to meet the various cognitive styles.

- Students' academic achievement can be improved by the use of interactive infographics due to their richness in material, multimedia approach, and interactivity that stimulate and communicate with learners' senses and positively affect their acquisition of information.

Keywords: static infographic, interactive infographic, cognitive style, reflective/impulsive, academic achievement, multimedia, Web 2.0, dual coding theory, cognitive load

\section{Introduction}

The ways in which information is presented and accessed have changed in the twenty-first century. There has been increasing interest in using the potential of technology to convey information visually to attract the attention of more audiences. This led to the need for new strategies and methods of teaching and learning that are more learner-centred (Davidson et al., 2014; Ismaeel \& Al Mulhim, 2019a). In turn, this has required teachers to find more varied ways to present content to students to facilitate information processing and encourage them to actively engage in their learning process. According to the information processing model, learning occurs when external stimuli attract an individual's attention, the information conveyed with these stimuli is recorded and organised in the short-term memory, and finally, it is stored in their longterm memory to be added to their existing knowledge (Baglama et al., 2017). As "different people tend to process the same information in different ways, using different areas of the brain, depending upon their cognitive style" (Riding et al., 1997, p. 219), presenting content in different modes to be more varied, interactive, flexible, and attractive is highly recommended to help students process information easily in accordance with their individual preferences.

Infographics are one of the more interesting modes of presenting information visually through diagrams, videos, charts, text images, and the like (Al-Mohammadi, 2017). There are many types of infographics, including static, interactive, and animation. Infographics have gained popularity, particularly in the education field (Ozdamli \& Ozdal, 2018), because they present a substantial amount of information in a fluent and easy-to-comprehend format (Hassan, 2016). Infographics can present information in an organised and attractive way and therefore be smoothly captured in the individuals' minds. Although the effectiveness of using infographics in education as one of several digital information presentation modes has been proven, cognitive styles may influence the level of learning from them (Lin et al., 2018). Therefore, cognitive styles must be considered as key definers of the ways and preferences of how an individual receives, analyses, and processes information in the acquisition of knowledge, which consequently affects their performance and achievement (Chiang, 2016; Lin et al., 2018; Shahsavar \& Hoon, 2011; Tayebinik \& Puteh, 2013). 
Several studies have recommended considering cognitive styles when designing learning environments (Ismaeel \& Al Mulhim, 2019b; Saeed et al., 2009; Uzunboylu \& Karagozlu, 2015) because students can benefit most from instruction when the format of information presentation suits their cognitive styles (Wylie \& Chi, 2014). In designing effective e-learning environments that take into account learners' characteristics and traits that impact their information processing, the role of students' cognitive styles becomes crucial, especially when assessing academic achievement. Reflective and impulsive cognitive styles are among the characteristics that affect how individuals learn and how they receive and process information. In this regard, this paper aims to explore the influence of static/interactive infographics on reflective/impulsive students' academic achievement.

\section{Literature review}

\section{Infographics in education}

Infographics are graphic visual representations of knowledge, data, and information. Importantly, visual representations clearly and quickly present complex information, such as graphs, maps and signs, in the fields of education, technical writing, journalism, and others (Afify, 2018; Ozdamli \& Ozdal, 2018; Yildirimm, 2016). Learning processes involve the transfer of information to students, and teaching materials play an important role (Yildirim, 2016). Therefore, infographics, as tools to assist learning, are significant because they enhance the transfer of knowledge to the students. According to Afify (2018), infographics have been used in e-learning environments, such as web-based learning, mobile learning, and social media platforms, which enable learning to take place at any time and place.

Infographics in the education context are supported by Clark and Paivio's (1991) theory of dual coding and Sweller et al.'s (2011) theory of cognitive load. Dual coding theory assumes that human memory consists of two systems for coding information - one for verbal representations and treatment, and the other for nonverbal (imagery) representations and treatment. According to Sweller et al.'s theory, learning occurs when a learner receives different information symbols through two different reception channels so that the information is processed through one of the two independent channels, one of which processes verbal information (written and audio text) and the other that processes non-verbal information (pictures and graphics). The information is then easier to retain and recall if using the dual coding system. When more than one coding channel is used, the learning level improves; the use of verbal and non-verbal information together facilitates learning and increases the number of elements of retrieval information, as one uses two types of mental representations (verbal and non-verbal).

Findings in the literature on infographics agree with the theory of dual coding. Dual coding helps draw the attention of learners into various visual kinds of information (Vanichvasin, 2013). Infographics facilitate learning, and they are perceived as more instructive than text (Yildirim, 2016). People comprehend images 60,000 times more than reading texts. Therefore, the incorporation of infographics into the classroom setting facilitates learning processes, data retrieval, and memorisation (Shafipoor et al., 2016).

Sweller et al.'s (2011) cognitive load theory assumes that the capacity and duration of working memory are limited. The working memory varies in processing a large amount of information and thus tends to split attention. Some information receives more attention than other as it is highlighted and processed while neglecting other information, which results in fragmenting the learner's attention and in turn leads to a high cognitive load on the working memory and thus impedes the learning process (Sweller, 2002). In light of this theory, infographics are assumed to present information to students through graphics and texts in a simple, organised, and attractive way. This allows students to concentrate on the most important information thereby reducing the cognitive load. This is supported by Korbach et al. (2017), who claim that excluding irrelevant information and focusing on the essential can reduce the cognitive load. The ability of infographics to reduce the cognitive load has been discussed and verified in various studies, such as those of Afify (2018), Dunlap and Lowenthal (2016), Martin et al. (2019), and Mohamed (2020). All these studies agree that students spent less time learning due to reduction of the cognitive load.

Infographics have demonstrated effectiveness in increasing the success of students in school when used as alternatives to traditional texts. Usually, infographics are more desirable, and both students and teachers have positive perceptions of them (Çif̧ci, 2016; Ozdamli \& Ozdal, 2018). Positive opinions lead to the 
development of learning environments, that then lead to positive performance and higher academic achievement (Çifçi, 2016; Mahmoudi et al., 2017; Vanichvasin, 2013). One challenge with the use of infographics in education is that it requires accurate designs based on scientific standards, otherwise, audiences may not get the best information out of the tools. Hassan (2016) and Yildirim (2016) emphasised the value of properly designed infographics for teaching complex science subjects that involve temporal and spatial data.

There are different types of infographics, including interactive and static. More importantly, infographics share critical similarities with each relying on visual representations to make the information known to their audiences. Static infographics combine images and texts to represent challenging concepts in visual elements, such as maps, charts, and graphics. Usually, static infographics serve as fixed resources, as they do not require interaction from users (Shaltout \& Fatani, 2017). In contrast, interactive infographics depend on the readers who are required to manipulate them by watching videos, selecting visual elements, or selecting answers. They are considered interactive as they call for user input and collect statistics, data, and other information (Shaltout \& Fatani, 2017).

The literature differs in determining the type of infographic that would be most effective in improving students' learning outcomes, although there are not many studies that highlight the comparison of infographic types (static versus interactive) in particular. Many have explored the effectiveness of a single type of infographic or have compared static or interactive infographics with other types, including animated infographics. Various studies confirm that static infographics are more effective. For example, Hassan (2016) conducted a study that formulated principles for creating meaningful infographics to communicate information successfully and effectively. His study also compared infographic types (static versus animated) to determine the most effective type when employed as a teaching-aid framework for complex science subjects. The results of this study revealed that using properly designed infographics could help in teaching complex science subjects that involve spatial and temporal data. The results also suggest that both infographic types have a significant impact on improving students' comprehension. Concerning the comparison of the two types, static infographics are more effective in communicating the subject and as a teaching-aid framework. This result agrees with the review of Mayer et al. (2005) that did not detect any preference for animated infographics over the static type. This was attributed to the extent of the information and data provided by animated infographics that sometimes is more than needed. On the other hand, static infographics provide an easier way to understand complex subjects. Additionally, in her comparison between static and animated infographics, Peters (2013) confirmed that the motion in animated infographics may inhibit students from comprehending the content fluently when they provide more than needed, whereas with a static infographic, they could read and decipher the information at their own pace. Thus, she suggested that the static type of infographics could be more effective when learning conceptual processes. Previous studies assert that static infographics allow students to visually navigate all the components at the same time. This enables students to discover relationships between these components much easier and leads to improving learning conceptual processes. The static type of infographics provides students with only the main data and information needed without unnecessary additions. This may decrease cognitive load leading to simpler cognitive tasks and information processing. As a consequence, the information can be retained longer in visual memory. Despite all these advantages, static infographics are not preferred when visualising complex science events and process topics (Hassan, 2016). Processes involving motion are hard to facilitate by static infographics. Moreover, because static infographics do not require interaction between students and the contents, they may lead to passive and inactive learning. The literature suggests that students tend to learn through electronic devices, such as mobile phones and tablets, that provide them more interactivity and allow them to engage in the learning process (Al Subeh et al., 2017; Demir \& Akpinar, 2018; Ismaeel \& Al Mulhim, 2019b; Zhu et al., 2018).

Among the studies favouring interactive infographics for teaching and learning, Alshehri and Ebaid (2016) conducted a study that aimed to investigate the influence of interactive infographics in teaching mathematics at an elementary school. Their findings revealed that the interactive infographic is an effective tool in teaching and learning mathematics for elementary students. Dur et al. (2014), moreover, in her review of literature on interactive infographics on the Internet, asserted that the interaction between users and static infographics is very limited to viewing and reading. She highlighted that interactive infographics involve myriad information and various applications that encourage interaction. Despite the intensity of information in interactive infographics, her review does not refer to cognitive overload that may occur as a consequence. Locoro et al. (2017) explored the differences between static and interactive infographics 
relating to users' perception and the use of static and interactive infographics in terms of their information, interaction, and design qualities. They chose three general topics of the participants' interests: weather, study, and work. The participants were split randomly into two groups. One group studied using static infographics and the other with fully configurable interactive infographics. The results favoured the interactive infographics. Sudarman et al. (2019) also confirmed that interactive infographic involves dynamic and realistic activities and simplifies information that can improve students' motivation. It helps students connect what is presented through interactive infographics to the information in their visual memory for processing when developing new experiences.

Previous studies have examined the lack of interaction in static designs. The interactive type usually contains more information and details, requires employing various digital applications that attract users for more interaction, and involves more functions that promote flexibility in searching a specific piece of formation. Moreover, users can control the extent to which they delve into the infographic to discover information and process it into their visual memory to develop new experiences. However, these studies do not address the cognitive overload issue that may occur when using interactive infographics due to the quantity of information presented and the duration needed to process it in students' minds. The researchers of the current study believe that such an issue may be overcome by a proper design of interactive infographics that includes the main points of the learning subject and excludes irrelevant points, allowing sufficient time for students to learn at their own pace.

Increasingly, the literature confirms the necessity of considering students' different cognitive styles when designing learning resources to meet students' varying learning needs and reach better learning outcomes (Chiang, 2016; Ismaeel \& Al Mulhim, 2019b; Tayebinik \& Puteh, 2013). Infographics involve the use of symbols, pictures, graphics, colours, and texts, which match the individual differences between students and their various cognitive styles (Sudarman et al., 2019). Towards this interest, this study examined the influence of two types of infographics — static and interactive — on students' cognitive styles.

\section{Cognitive styles}

According to Riding and Rayner (2013), the cognitive style refers to how an individual thinks and processes information. People respond to information and situations in an automatic way. Cognitive style is usually a constant aspect of individuals' learning performance that affects their cognitive, affective, intellectual, and psychological behaviours (Chiang, 2016; Shahsavar \& Hoon, 2011) and their ultimate achievement in learning settings (Riding \& Rayner, 2013). It is a key predictor of how a student will learn and interact with information (Ismaeel \& Al Mulhim, 2019b). Reflectivity-impulsivity style refers to different cognitive styles defined primarily as a conceptual tempo variable considering the time an individual takes to look at alternative solutions before selecting one in a situation with high outcome uncertainty (Kagan, 1965a). In other words, it is a characteristic of the human cognitive system that is measured by combining the time taken to make a decision and the quality of the decision made to solve a given problem. Reflectivityimpulsivity thinking determines the speed people take to make decisions (Ault et al., 1972). According to Kagan et al. (1966, p. 583), a reflective individual "considers the differential validity of alternative answers, makes fewer errors in reading prose or in recalling serially-learned material, and persists longer with difficult tasks." They aim to avoid errors and try to inhibit potentially incorrect hypotheses. An impulsive individual is minimally concerned about mistakes and makes decisions quickly. The time taken to evaluate potential solution hypotheses in the problem-solving process illustrates the degree of reflectivity versus impulsivity of individuals. Influenced by their particular reflectivity-impulsivity style, reflective individuals are slower to reach a decision, but normally score higher than average in the quality of their decision. Typically, they are the students who take an extended time to complete a task assigned, but they produce accurate work (Siegelman, 1969). Impulsive individuals, on the other hand, are those who test faster than average but will score lower than average. These students seem to be in a rush and frequently miss finding the correct answers. People's reflectivity-impulsivity style determines their behaviours and approaches to problem-solving. Specifically, students may apply the same critical thinking to global approaches, but those with impulsive cognition will typically have difficulty delaying the gratification of completing the task, and reflective students will be more analytical in dealing with problematic situations.

The reflective/impulsive style is based on Allport's theory of personality that emphasises motivation, internal cognition, and the uniqueness of individuals in determining behaviour (Schultz \& Schultz, 2017). Similarly, the reflective/impulsive style shows the significance of personality in determining whether 
individuals act reflectively by thinking through the issues and considering responses before acting, or if they act impulsively, making decisions rapidly without first thinking through the situation (Davidson, 1984). Reflectivity-impulsivity cognitive style is critical as it recognises the differences in the way people organise, gather, and process information and apply it to problem-solving (Wang \& Lu, 2018). Simply put, different people use different qualitative adaptive processes, as evidenced by the time taken to identify an object and their accuracy in identification.

According to Wang and $\mathrm{Lu}$ (2018), cognitive styles, including reflectivity-impulsivity style, are essential in elaborating, synthesising, analysing, and evaluating specific learning information, which, in turn, contributes to academic success. Much of the literature reviewed examined the influence of emphasising students' cognitive styles, such as reflectivity-impulsivity, in efforts to improve their learning skills and outcomes. For example, Umaru (2013) conducted a study to investigate the influence of reflectivityimpulsivity on students' achievement in mathematics. The author found that reflective students achieved higher scores in mathematics and other science-related disciplines while impulsive students performed poorly in the same subjects. Similarly, Nietfeld and Bosma (2003) examined students' self-regulation as they attempted to complete the SAT exam. The results showed that reflective students self-regulate their responses, which contributed to higher achievement in academics, as opposed to impulsive students who made decisions rapidly. Contrary to performance and achievement, motivational orientations are significant products of impulsivity (Strack \& Deutsch, 2004). This is particularly true of students who are impulsedriven by the motivation to complete tasks earlier and attain higher performance.

In summary, reflectivity yields greater benefits for student learning than impulsivity. For this reason, instructors need to help their students develop and incorporate reflective approaches into their learning methodologies, as they lead to higher accuracy than impulsivity. Cognitive styles are perceived an important component of a learning situation (Abidin et al., 2011), as identifying students' preferred style of learning helps teachers optimise the educational process (Fairhurst \& Fairhurst, 1995). Therefore, teachers should develop and employ various strategies and means to meet and support the different cognitive styles of their students. From this perspective, this study focused on investigating the influence of static/interactive infographics on both reflective and impulsive students' academic achievement.

\section{Research questions and hypotheses}

This study's primary aim was to explore the influence of static/interactive infographics on reflective/impulsive students' academic achievement. The study will investigate the following questions:

1. What is the influence of the infographic type (static/interactive) on students' academic achievement?

2. What is the influence of the cognitive style (reflective/impulsive) on students' academic achievement?

3. What is the influence of the interaction between the infographic type (static/interactive) and the cognitive style (reflective/impulsive) on students' academic achievement?

To answer these questions, the following hypotheses were proposed:

H1: There are no statistically significant differences at level 0.05 in academic achievement scores due to different types (static/interactive) of infographics.

$\mathrm{H} 2$ : There are no statistically significant differences at level 0.05 in academic achievement scores due to different cognitive styles (reflective/impulsive).

H3: There are no statistically significant differences at level 0.05 in academic achievement scores due to the main interaction between infographic type (static/interactive) and cognitive style (reflective/impulsive).

\section{Experiment}

\section{Methodology}

The experimental approach was applied to determine the influence of interaction between the infographic type (static/interactive) and the cognitive style (reflective/impulsive) on students' academic achievement. 


\section{Design of the two types of infographics (static/interactive)}

The design of the infographics was built on Branch's (2009) analysis, design, development, implementation, and evaluation (ADDIE) model in constructing the experimental treatments.

The analysis stage

- Setting the overall goal of learning. The general goal of learning in this study is an introduction to Web 2.0.

- Identifying the learners' characteristics. The characteristics of the participants were similar to the extent that they were college students approximately the same age (17-18 years old), with basic technology skills. Participants selected were third-semester students in the College of Education enrolled in an educational technology course. They were unfamiliar with the educational content of Web 2.0, but possessed basic computer skills and those needed for using smartphones and their applications in general.

- Analysis of the technological environment. The technological environment requires smartphones or tablets with Internet access.

The design stage

- Setting behavioural objectives. Web 2.0 was selected as the content for both static and interactive infographics. A list of 11 behavioural objectives of the learning topic was presented to a group of eight educational technology experts to assess the validity and formulation of the objectives. The percentage of the average score of each objective ranged from $75 \%$ to $100 \%$. The average was calculated of all results of the objectives. The final result reflected that the experts agreed on the objectives' validity at around $97 \%$. Some modifications to the wording of the objectives were suggested. Applying these modifications, a final version was finalised.

- Identifying the learning content. The learning content for the infographic about Web 2.0 was selected, including definition, characteristics, differences between Web 1.0 and Web 2.0, advantages and disadvantages, Web 2.0 technologies, and Web 2.0 services.

- The learning content was prepared in its initial form and presented to a group of eight educational technology experts to assess the extent to which it was relevant to the behavioural objectives, and whether it was adequate and could achieve the objectives. The scientific validity and clarity of the content against the relevancy and adequacy dimensions were also sought. The average scores of each dimension were calculated and were $98 \%$ and $94 \%$, respectively. The experts suggested some modifications to the content. The modifications were applied.

- Designing the infographics. Images and drawings were identified and collected for use in designing the infographics. The infographics were initially designed.

The development stage

- Producing static infographics. The infographics were prepared in their final form using Microsoft Office Publisher and reviewed by a group of five experts in the field of educational technology who were colleagues experienced in designing infographics and employing them in education. The required amendments were made. The infographic in Figure 1 served as a static example on its own. Using Microsoft Office Word, text-based content books were produced to be presented with it. The textbook focuses on the main points of Web 2.0. 


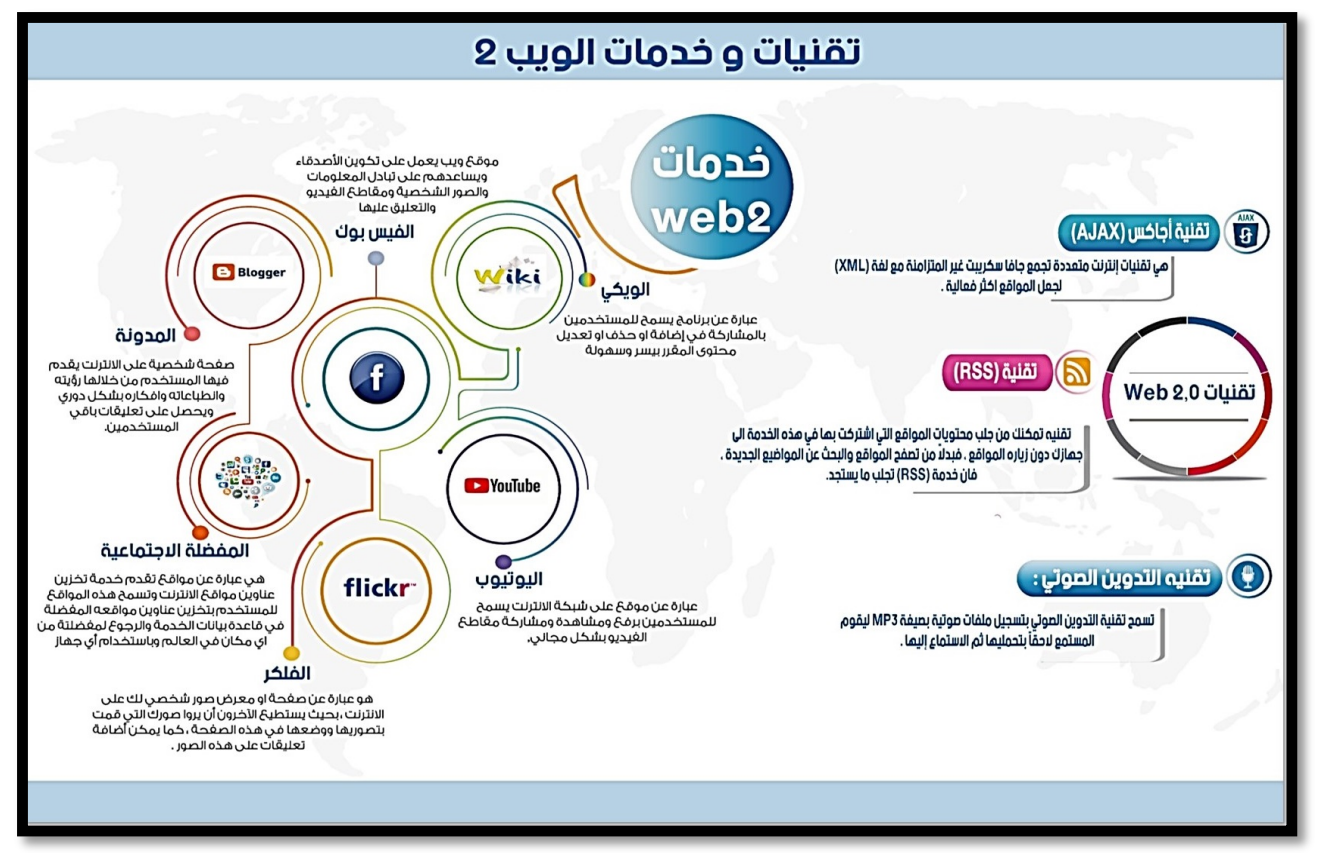

Figure 1. Static infographic

- Producing the interactive infographic. Another copy of the static infographic was made interactive by applying augmented reality technology linking the static infographic to video clips. The textbooks and videos were the same in terms of content focusing on the main points of Web 2.0 and different in terms of presentation method, that is, the videos consisted of multimedia, including texts, animation, sound, and pictures. Several applications, including Powtoon, Animaker, and GoAnimate, were used to produce video clips linked to the interactive infographic. The video clips were also reviewed by a group of experts and necessary amendments were implemented. For the augmented reality technology, the HP Reveal mobile application was employed, and the video clips were linked to pre-identified points on the infographics (Figure 2).

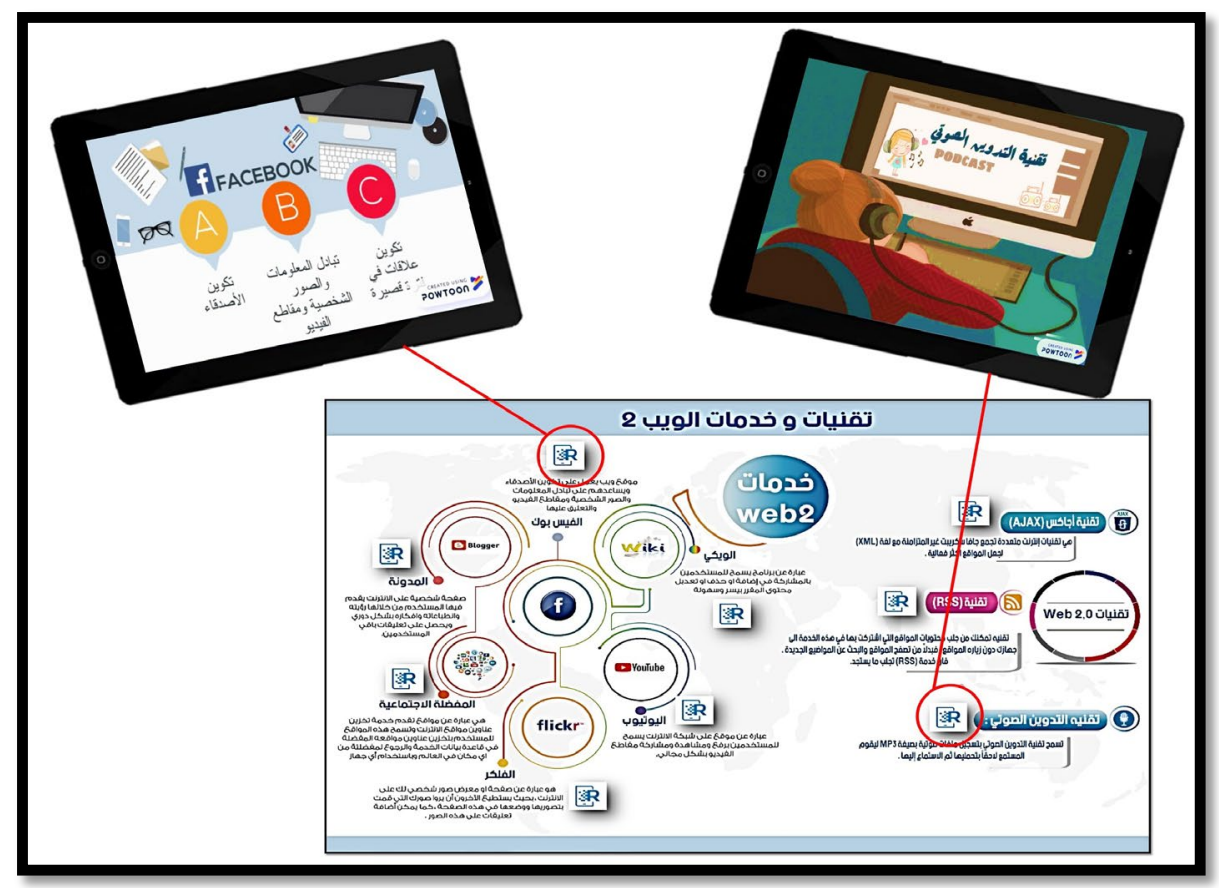

Figure 2. Interactive infographic 
The implementation stage

A pilot study was conducted on a sample of 20 randomly selected students in the College of Education not involved in the main experiment to ensure they had no prior knowledge of the learning content, as indicated by a knowledge pre-test on the topic of Web 2.0. Kagan's Matching Familiar Figures Test (1965b) was applied to divide this pilot sample into two groups according to cognitive style (reflective/impulsive). The pilot sample had the same characteristics as the main study community. They were treated with the research instruments to confirm suitability, clarity, time required, reliability, and validity.

The evaluation stage

To ensure the validity of all the previous stages, a structural evaluation was applied, taking into account the results of the pilot experiment. The participants, treatments, and instruments are described below.

\section{Participants}

Eighty undergraduate students participated in the experiment; all were enrolled in a course called Educational Technology at the College of Education at King Faisal University. All ethics approval forms and disclaimers adhere to the Ethics of Scientific Research, issued by the Permanent Committee of Ethics of Scientific Research at King Faisal University. The experiment was carried out during the second semester of the 2018-2019 academic year. The participants were divided into two groups based on their reflective/impulsive cognitive style.

\section{Independent variables}

Two independent variables were used in the study.

\section{Infographic type}

Two types of infographic were used: (1) static (pictures, texts, and drawings), versus (2) interactive (the same as the static infographic but linked to videos through augmented reality technology). Four experimental treatments were designed in light of the types of infographic and cognitive styles:

1. Static infographic with reflective students (SR),

2. Static infographic with impulsive students (SI),

3. Interactive infographic with reflective students (IR), and

4. Interactive infographic with impulsive students (II).

Reflective/impulsive cognitive styles

In order to classify the study's sample into reflective and impulsive students, Kagan's Matching Familiar Figures Test (MFFT) (1965b) was considered in its Arabic version, which was translated and adapted by Alfaramawi (1985) to match Arabic society. The test consisted of 22 items; 2 were sample items, and 20 were measuring items. Every item contained a model figure and eight versions of one exact copy. The students were asked to identify the version that matched the model figure. Eight attempts were made for each item. The samples were tested one by one, and response latency for the first choice and the number of errors were recorded for each item. At the end of the test, the mean of response latency and the number of errors were calculated and used as classifying criteria:

- Reflective students $(n=40)$ : Response latency for the first choice is above average, and the number of errors is lower than the average.

- Impulsive students $(n=40)$ : Response latency for the first choice is less than the average and the number of errors is above the average.

- Students who were outside this classification $(n=9)$ were excluded from the sample.

With respect to the reliability of the test, Alfaramawi (1985) re-applied the test on the sample and reported that correlation coefficients were 0.85 for latency and 0.68 for number of errors. This is a high value, indicating that the test is highly reliable. The present instrument's reliability was calculated using the retest method on the pilot sample of students. It found correlation coefficients of the pilot sample at 0.91 for latency and 0.94 for number of errors. These scores indicated highly significant reliability. 


\section{Dependent variables}

\section{Academic achievement}

The knowledge test consisted of 20 multiple-choice items about Web 2.0. It was designed to measure the sample's academic achievement. Each item counted as one mark, meaning total marks for the test were 20. The test was initially judged by eight experts of educational technology to assess the truth of the items, their relevance to the content, their coverage of educational goals, and precision. The experts concluded that the test was appropriate at $93 \%$. Some language modifications were required, and the test was ready to be applied to the pilot sample.

To calculate the reliability of the test, it was applied to the pilot sample of 20 students. Using the split-half reliability of the items, they were grouped into odd and even questions. Reliability was calculated using Spearman and Brown's equation and the correlation coefficient between the two parts. The correlation coefficient was 0.87 , which was an acceptable result. The average duration of the test was 45 minutes.

\section{Experimental procedure and data collection}

1. Kagan's MFFT was applied to 89 third-semester students enrolled in an educational technology course at the College of Education at King Faisal University in order to classify students according to their cognitive styles from impulsive (40 students) to reflective (40 students). Nine students were excluded from the sample because they were outside the classification.

2. The impulsive group was then divided randomly into two groups of 20 according to infographic type (static/interactive). Similarly, the reflective group was divided randomly into two groups of 20 according to infographic type (static/interactive). Thus, the research sample consisted of four groups, each with 20 students. The knowledge pre-test was applied to all groups to ascertain the homogeneity among them.

3. An introductory meeting was held with the SR and SI groups to explain the mechanism for the use of static infographics, and students were further referred to the related information in the textbook.

4. An introductory meeting was held with the IR and II groups to explain the use of interactive infographics, to install the HP Revel application onto the students' smart devices, and to provide them with the login information prepared by the researchers.

5. Application of the experiment for all four groups took 15 days between 3 and 17 February 2019 .

6. The knowledge post-test of achievement was applied to all research groups. After the basic research experiment was implemented, the researchers recorded the scores of the test to conduct statistical analyses.

7. Data were processed and statistically analysed using the two-way ANOVA test to determine the significance of differences among the groups. The Sheffe test was applied to compare groups in pairs and to detect significant differences.

\section{Results}

\section{Homogeneity among the groups}

Homogeneity among the four groups was determined using the one-way ANOVA analysis to find significant differences between the mean scores of the knowledge pre-test, as shown in Table 1.

Table 1

One-way ANOVA for the groups on the knowledge pre-test

\begin{tabular}{lrrrrr}
\hline & Sum of Squares & $d f$ & Mean square & $F$ & Sig \\
\hline Between groups & 8.537 & 3 & 2.846 & & \\
Within groups & 123.450 & 76 & 1.624 & 1.752 & 0.164 \\
Total & 131.987 & 79 & & & \\
\hline
\end{tabular}

The one-way ANOVA analysis revealed that there were no statistically significant differences between the groups before conducting the experiment $(f=1.752, p>0.05)$, thus the groups were homogeneous in their knowledge about the learning content. 


\section{Academic achievement}

The results of the research groups were analysed for academic achievement in terms of mean and standard deviations, and according to the current research variables. Table 2 shows the results of this analysis.

Table 2

Means and standard deviations of the knowledge post-test (academic achievement results) according to the dependent variables

\begin{tabular}{|c|c|c|c|c|c|c|c|c|c|c|}
\hline \multirow{3}{*}{ Groups } & & \multicolumn{6}{|c|}{ Types of infographic } & \multirow{2}{*}{\multicolumn{3}{|c|}{ Total }} \\
\hline & & \multicolumn{3}{|c|}{ Static } & \multicolumn{3}{|c|}{ Interactive } & & & \\
\hline & & $M$ & $S D$ & $N$ & $M$ & $S D$ & $N$ & $M$ & $S D$ & $N$ \\
\hline Cognitive & Reflective & 13.60 & 1.39 & 20 & 17.80 & 1.99 & 20 & 15.70 & 2.72 & 40 \\
\hline style & Impulsive & 10.75 & 1.71 & 20 & 8.10 & 1.17 & 20 & 9.43 & 1.97 & 40 \\
\hline Total & & 12.17 & 2.11 & 40 & 12.95 & 5.17 & 40 & 12.56 & 3.94 & 80 \\
\hline
\end{tabular}

Two-way ANOVA analysis was used to calculate significant differences between the mean scores of the research groups and the interaction between them, according to the independent variables of infographic type (static/interactive) and cognitive style (reflective/impulsive). Table 3 shows the results of the two-way ANOVA analysis of academic achievement.

Table 3

Results of two-way ANOVA for the knowledge post-test (academic achievement results)

\begin{tabular}{lrrrrrr}
\hline Source & Sum of squares & $d f$ & Mean square & $F$ & Sig & $\begin{array}{c}\text { Partial eta } \\
\text { square }\end{array}$ \\
\hline Type of infographic & 12.013 & 1 & 12.013 & 4.717 & 0.033 & 0.058 \\
Cognitive style & 787.513 & 1 & 787.513 & 309.227 & 0.000 & 0.803 \\
Cognitive style *type & 234.613 & 1 & 234.613 & 92.124 & 0.000 & 0.548 \\
of infographic & 193.550 & 76 & 2.547 & & & \\
Error & 13853.00 & 80 & & & & \\
Total & & & & & \\
\hline
\end{tabular}

First hypothesis

Table 3 shows that there are statistically significant differences among average academic achievement scores attributable to the type of infographics (static/interactive) $(f=4.717, p<0.05)$ favouring the interactive infographic, as shown in Table 2, in which the total mean scores of academic achievement of the interactive infographic $(M=12.95, S D=5.17)$ are greater than those of the static infographic $(M=$ $12.17, S D=2.11$ ). The size of effect was calculated by the partial eta squared coefficient (Cohen's $d=$ 0.058), which indicates a small effect for the interactive infographic intervention. Therefore, the first hypothesis was rejected.

Second hypothesis

Table 3 shows that there are statistically significant differences in academic achievement scores attributable to the difference in cognitive styles (reflective/impulsive) $(f=309.227, p<0.05)$ favouring reflective students, as shown in Table 2. Total mean scores of academic achievement of the reflective students $(M=$ $15.70, S D=2.72)$ were higher than the scores of the impulsive students $(M=9.43, S D=1.97)$. This confirms that the cognitive style has an impact on students' academic achievement. The effect size was calculated by the partial eta squared coefficient (Cohen's $d=0.803$ ), which indicates a large effect attributed to the cognitive style intervention. Thus, the second hypothesis was rejected.

Third hypothesis

Table 4 reveals statistically significant differences among average academic achievement scores of the research groups attributable to interaction between the independent variables $(f=92.124, p<0.05)$. Using the Scheffe test, the difference was found in favour of the IR group $(M=17.80, S D=1.99)$. Consequently, the third null hypothesis was rejected. 
Table 4

Multiple comparisons between infographic types and cognitive styles in knowledge post-test (academic achievement results)

\begin{tabular}{|c|c|c|c|c|c|c|}
\hline Group & $M$ & $S D$ & SR & SI & IR & II \\
\hline SR & 13.60 & 1.39 & & sig & sig & sig \\
\hline SI & 10.75 & 1.71 & $\operatorname{sig}$ & & sig & sig \\
\hline IR & 17.80 & 1.99 & sig & sig & & sig \\
\hline II & 8.10 & 1.17 & sig & sig & sig & \\
\hline
\end{tabular}

Results reported in Table 4 show significant differences between all research groups with the best results in:

- The third group (IR) - interactive infographics with reflective students $(M=17.80, S D=1.99)$,

- The first group (SR) - static infographics with reflective students $(M=13.60, S D=1.39)$,

- The second group (SI) - static infographics with impulsive students $(M=10.75, S D=1.71)$, and

- The fourth group (II) - interactive infographics with impulsive students $(M=8.10, S D=1.17)$.

The effect size was calculated by the partial eta squared coefficient (Cohen's $d=0.548$ ), which indicates a large effect attributed to the interaction between the infographic type and the cognitive style. The results from Table 4 suggest that infographic type and cognitive style both may impact students' academic achievement in favour of reflective students who learned using interactive infographics. To assess further the effect of the study intervention, the pre- and post-test of each group were calculated as presented in Table 5.

Table 5

Paired sample t-test of knowledge pre-and post-tests (academic achievement results)

\begin{tabular}{|c|c|c|c|c|c|c|c|c|}
\hline Groups & & $N$ & $M$ & $S D$ & $S E$ & $t$ & $d f$ & Sig \\
\hline \multirow{2}{*}{ SR } & Pre-test & 20 & 3.55 & 1.276 & 0.285 & \multirow{2}{*}{21.256} & \multirow{2}{*}{19} & \multirow{2}{*}{0.000} \\
\hline & Post-test & 20 & 13.60 & 1.392 & 0.311 & & & \\
\hline \multirow{2}{*}{ SI } & Pre-test & 20 & 3.30 & 1.455 & 0.325 & \multirow{2}{*}{27.074} & \multirow{2}{*}{19} & \multirow{2}{*}{0.000} \\
\hline & Post-test & 20 & 17.80 & 1.989 & 0.445 & & & \\
\hline \multirow{2}{*}{ IR } & Pre-test & 20 & 2.85 & 1.268 & 0.284 & \multirow{2}{*}{17.459} & \multirow{2}{*}{19} & \multirow{2}{*}{0.000} \\
\hline & Post-test & 20 & 10.75 & 1.713 & 0.383 & & & \\
\hline \multirow{2}{*}{ II } & Pre-test & 20 & 2.75 & 1.070 & 0.239 & \multirow{2}{*}{15.286} & \multirow{2}{*}{19} & \multirow{2}{*}{0.000} \\
\hline & Post-test & 20 & 8.10 & 1.165 & 0.261 & & & \\
\hline
\end{tabular}

Table 5 presents the paired-samples $t$-test and descriptive data of the four independent groups' (SR, SI, IR, and II) performance on both pre- and post-tests. These data confirm the validity of the study intervention and its effect on academic achievement as it reveals significant differences $(p<0.05)$ between the mean scores of the pre- and post-tests of each group in favour of the post-test. This finding confirms previous findings from the partial eta squared coefficients.

\section{Discussion}

\section{First hypothesis}

The first hypothesis reflects statistically significant differences in academic achievement scores due to the type of infographics (static/interactive) in favour of the interactive infographic (Table 2). This result can be attributed to the characteristics of the interactive infographics that are rich with information and details that, in turn, rely upon multimedia. Multimedia draws the attention of more of the learners' senses, thereby enhancing their knowledge acquisition and increasing its retention. Moreover, these visual stimuli encourage learners to engage in more interaction with and immersion in the learning setting, leading to increased motivation to learn and more successful information acquisition. This agrees with the dual coding theory that stated that presenting information through multimedia facilitates knowledge construction in a learner's mind by making connections between the various forms of information (verbal and non-verbal). Presenting information this way helps transfer knowledge to the learner's memory in multiple forms, which then can be retrieved easily and in more than one way (Clark \& Paivio, 1991). 
Considering the theory of cognitive load, the studies of Afify (2018), Dunlap and Lowenthal (2016), Martin et al. (2019), and Mohamed (2020) reported that cognitive load could be reduced using infographics. The infographics were found to highlight the most important points of the study subject and exclude irrelevant information. This may help avoid splitting and distracting students' attention, which could lead, in turn, to reducing the information load to process. More specifically, although the literature has little research comparing infographic types (static versus interactive) and does not extensively explore the cognitive load resulting from the interactive type in particular, the findings of the current study are not surprising. They provide evidence of the superiority of the interactive type in terms of academic achievement and indirectly implies a lower cognitive load. This result may be attributed to the distinctive characteristics of the interactive style, such as interactivity and attractiveness, especially with the use of tablets and mobile devices that motivate students to learn. It could also be related to the good design of the infographic itself and its interactive components (elements of augmented reality). Similar to the static type, the interactive type's focus was on the main information, and no irrelevant or unnecessary data were included. Students were also allowed to interact with the infographic and its interactive components according to their abilities and pace in learning.

This result is in line with the findings of other studies (Alshehri \& Ebaid, 2016; Dur, 2014; Locoro et al., 2017; Sudarman et al., 2019) that asserted the superiority of interactive infographics over static in educational settings due to the static type's limitations - lack of movement, lack of interaction, and limited ability to attract learners' attention.

\section{Second hypothesis}

The results of the second hypothesis revealed statistically significant differences among the average academic achievement scores due to differences in cognitive styles (reflective/impulsive) in favour of the reflective students. This result can be attributed to the distinctive characteristics of reflective students. They are typically more settled, serious, focused, and interested in the smallest details of information provided, in terms of handling, processing, analysing, representing, and integrating them into their knowledge base. This has a positive impact on increasing their level of learning and academic achievement. This result is supported by the findings of Davidson (1984), Nietfeld and Bosma (2003), Siegelman (1969), and Umaru (2013). These researchers have indicated that reflective students usually think carefully and in-depth about the issues and tasks assigned to them, which leads to achieving better results.

\section{Third hypothesis}

Examination of the third hypothesis (Table 4) suggests that infographic type and cognitive style both have a positive impact on students' academic achievement. Nevertheless, the results showed that reflective students who learned using interactive infographics (IR group) outperformed the other groups. This result indicates that the IR group had the highest degree of engagement of the experimental groups.

Despite the lack of studies exploring interactions among the infographic types (static and interactive) and cognitive styles (reflective and impulsive), this result was expected and looks reasonable. This can be concluded based on the first and second findings of the current study reporting the superiority of reflective students over impulsive students as well as the superiority of interactive infographics over static. This reflects an alignment of interactive infographics with the characteristics of reflective students who learn patiently and pay careful and adequate attention to different components (augmented reality items) associated with interactive infographics, focus on the precise details. The interactive infographic employs tablets and mobile devices that have proven to attract students' attention and motivate them towards learning. Al Subeh et al. (2017), Demir and Akpinar (2018), Ismaeel and Al Mulhim (2019b), and Zhu et al. (2018) suggest that students usually have positive attitudes towards the use of modern technologies and mobile applications.

\section{Limitations}

The study has certain limitations. Only two types of infographics - static and interactive-were examined. The study does not investigate animated infographics. The infographics content was about Web 2.0 in particular. The present study, moreover, focused on only the reflectivity/impulsivity cognitive style. The sample was limited to third level undergraduate students who were enrolled in a course called Educational 
Technology at the College of Education at King Faisal University, Saudi Arabia, during the second semester of the 2018-2019 academic year. There is a possibility that if one or more of these conditions changed, the findings would be different. Therefore, generalising the findings of this study should be done with caution. The study explored the influence of the infographic types (static versus interactive) and the cognitive style (reflective versus impulsive) on academic achievement only.

\section{Conclusion}

This study explored the influence of static/interactive infographics on reflective/impulsive students' academic achievement. The study emphasised the importance of taking into account the cognitive style of the learners as a key element when designing learning resources to meet students' learning needs and improve learning outcomes. However, there is a gap in the literature that highlights the design of different types of infographics as a modern form of presenting information in learning settings and their effects on students with different cognitive styles (i.e., reflective/impulsive).

The findings of the current study demonstrated the superiority of interactive infographics over the static type in improving academic achievement. This result may be attributed to the design of interactive infographics being based on multimedia that attract students' interest and encourage interaction (Alshehri \& Ebaid, 2016; Dur et al., 2014; Locoro et al., 2017; Sudarman et al., 2019). The result could be because of the appropriate design of the interactive infographic and its interactive components, videos associated with augmented reality technology. They contain the main information about the learning content and exclude any irrelevant and unnecessary information. This helps students focus on the content provided and does not split their attention. Consequently, this may reduce cognitive load and provide more opportunities to acquire knowledge via several methods. Additionally, the results showed that reflective students outperformed impulsive students in achievement with both static and interactive infographics. Reflective students are known to be more patient, accurate, careful, deliberate, and serious in capturing details in the information available to them (Davidson, 1984; Nietfeld \& Bosma, 2003; Siegelman, 1969; Umaru, 2013). Further, there was significant interaction between the interactive infographics and reflective students. This result agrees with the previous results of the current study revealing the superiority of interactive infographics over static presentations as well as the superiority of reflective students over impulsive students. This may be due to the high degree of alignment between the nature of interactive infographics in presenting information and the students' cognitive styles.

This study may be valuable for educators and designers of learning resources in selecting suitable educational materials with the aim of tailoring them to a range of cognitive styles of students. Further investigation into this area is essential to fill in the gaps, such as examining other types of infographics (e.g., animated) and assessing their effect on learning outcomes (i.e., performance, attitudes, motivation, and retention). Likewise, it is recommended that more extensive studies explore the impact of infographics on other cognitive style parameters, such as field dependency/independency, ambiguity tolerance, and locus of control, with an eye on assessing the cognitive load associated with the use of different types of infographics and how to minimise it.

\section{References}

Abidin, M. J. Z., Rezaee, A. A., Abdullah, H. N., \& Singh, K. K. B. (2011). Learning styles and overall academic achievement in a specific educational system. International Journal of Humanities and Social Science, 1(10), 143-152. https://www.semanticscholar.org/paper/Learning-Styles-and-OverallAcademic-Achievement-in-Jafre-Abidin/d37e6a97e55fbfb79f2799e144948e3e571f6318

Afify, M. K. (2018). The effect of the difference between infographic designing types (static vs. animated) on developing visual learning designing skills and recognition of its elements and principles. International Journal of Emerging Technologies in Learning (iJET), 13(9), 204223.https://doi.org/10.3991/ijet.v13i09.8541

Alfaramawi, H. A. (1985). Guide of matching familiar figures test. Egyptian Angelo Library.

Al-Mohammadi, N. (2017). Effectiveness of using infographics as an approach for teaching programming fundamentals on developing analytical thinking skills for high school students in the city of Makkah in Saudi Arabia. Global Journal of Educational Studies, 3(1), 22-42.

https://doi.org/10.5296/gjes.v3i1.10854 
Alshehri, M. A., \& Ebaid, M. (2016). The effectiveness of using interactive infographic at teaching mathematics in elementary school. British Journal of Education, 4(3), 1-8. https://www.semanticscholar.org/paper/THE-EFFECTIVENESS-OF-USING-INTERACTIVEINFOGRAPHIC-Alshehri-Ebaid/7643bb26047cebe1 eefc1b8f47d3e88030ae68ae

Al Subeh, Z., Alali, F., \& Awaisu, A. (2017). Attitudes towards using smart devices and medical applications among pharmacy students, preceptors and faculty members in Jordan. Pharmacy Education, 17(1), 308-315. https://pharmacyeducation.fip.org/pharmacyeducation/article/view/544/443

Ault, R. L., Crawford, D. E., \& Jeffrey, W. E. (1972). Visual scanning strategies of reflective, impulsive, fast-accurate, and slow-inaccurate children on the Matching Familiar Figures Test. Child Development, 43(4), 1412-1417. https://doi.org/10.2307/1127527

Baglama, B., Yucesoy, Y., Uzunboylu, H., \& Özcan, D. (2017). Can infographics facilitate the learning of individuals with mathematical learning difficulties. International Journal of Cognitive Research in Science, Engineering and Education, 5(2), 119-128. https://doi.org/10.5937/IJCRSEE1702119B

Branch, B.M. (2009). Instructional design: The ADDIE approach. Springer Science + Business Media, LLC. https://doi.org/10.1007/978-0-387-09506-6

Chiang, H. H. (2016). A study of interactions among ambiguity tolerance, classroom work styles, and English proficiency. English Language Teaching, 9(6), 61-75. https://doi.org/10.5539/elt.v9n6p61

Çifçi, T. (2016). Effects of infographics on students' achievement and attitude towards geography lessons. Journal of Education and Learning, 5(1), 154-166. https://doi.org/10.5539/jel.v5n1p154

Clark, J. M., \& Paivio, A. (1991). Dual coding theory and education. Educational Psychology Review, 3(3), 149-210. https://doi.org/10.1007/bf01320076

Davidson, N., Major, C. H., \& Michaelsen, L. K. (2014). Small-group learning in higher educationcooperative, collaborative, problem-based, and team-based learning: An introduction by the guest editors. Journal on Excellence in College Teaching, 25(3\&4), 1-6. https:/ctl.oregonstate.edu/sites/ctl.oregonstate.edu/files/small group learning in higher education.pdf

Davidson, W. B. (1984). Personality correlates of the matching familiar figures test in adults. Journal of Personality Assessment, 48(5), 478-482. https://doi.org/10.1207/s15327752jpa4805 4

Demir, K., \& Akpinar, E. (2018). The effect of mobile learning applications on students' academic achievement and attitudes toward mobile learning. Malaysian Online Journal of Educational Technology, 6(2), 48-59. https://doi.org/10.17220/mojet.2018.02.004

Dunlap, J. C., \& Lowenthal, P. R. (2016). Getting graphic about infographics: Design lessons learned from popular infographics. Journal of Visual Literacy, 35(1), 42-59. https://doi.org/10.1080/1051144X.2016.1205832

Dur, B. İ. U., Filipczak-Bialkowska, A., Bresciani, S., Ge, J., Niu, Y., Othman, A., \& Wils, D. (2014). Interactive infographics on the internet. Online Journal of Art and Design, 2(4), 1-14. http://www.adjournal.net/articles/24/241.pdf

Fairhurst, A. M., \& Fairhurst, L. L. (1995). Effective teaching, effective learning. Davies-Black Publishing.

Hassan, H. G. (2016). Designing Infographics to support teaching complex science subject: A comparison between static and animated Infographics (Masters thesis). Iowa State University, IA. https://doi.org/10.31274/etd-180810-5344

Ismaeel, D. A., \& Al Mulhim, E. N. (2019a). Impact of e-learning strategies to design e-portfolio on achievement motivation and product quality. International Journal of Distance Education Technologies (IJDET), 17(2), 59-73. https://doi.org/10.4018/ijdet.2019040104

Ismaeel, D. A., \& Al Mulhim, E. N. (2019b). Influence of augmented reality on the achievement and attitudes of ambiguity tolerant/intolerant students. International Education Studies, 12(3), 59-70. https://doi.org/10.5539/ies.v12n3p59

Kagan, J. (1965a). Impulsive and reflective children: Significance of conceptual tempo. In J. D. Krumboltz (Ed.), Learning and the educational process (pp. 133-161). Rand McNally.

Kagan, J. (1965b). Matching familiar figures test. Harvard University.

Kagan, J., Pearson, L., \& Welch, L. (1966). Conceptual impulsivity and inductive reasoning. Child Development, 37(3), 583-594. https://doi.org/10.2307/1126680

Korbach, A., Brünken, R., \& Park, B. (2017). Measurement of cognitive load in multimedia learning: A comparison of different objective measures. Instructional science, 45(4), 515-536.

https://doi.org/10.1007/s11251-017-9413-5 
Lin, C. C., Huang, I., \& Wu, S. H. (2018). Effects of dietary infographics and cognitive styles on learners information processing. Proceedings of the 7th International Congress on Advanced Applied Informatics, Yongo, 358-361. https://doi.org/10.1109/IIAI-AAI.2018.00077

Locoro, A., Cabitza, F., Actis-Grosso, R., \& Batini, C. (2017). Static and interactive infographics in daily tasks: A value-in-use and quality of interaction user study. Computers in Human Behavior, 71, 240257. https://doi.org/10.1016/j.chb.2017.01.032

Mahmoudi, M. T., Mojtahedi, S., \& Shams, S. (2017). AR-based value-added visualization of infographic for enhancing learning performance. Computer Applications in Engineering Education, 25(6), 10381052. https://doi.org/10.1002/cae.21853

Martin, L. J., Turnquist, A., Groot, B., Huang, S. Y., Kok, E., Thoma, B., \& van Merriënboer, J. J. (2019). Exploring the role of infographics for summarizing medical literature. Health Professions Education, 5(1), 48-57. https://doi.org/10.1016/i.hpe.2018.03.005

Mayer, R. E., Hegarty, M., Mayer, S., \& Campbell, J. (2005). When static media promote active learning: Annotated illustrations versus narrated animations in multimedia instruction. Journal of Experimental Psychology: Applied, 11(4), 256. https://doi.org/10.1037/1076-898x.11.4.256

Mohamed, A. A. A. E. F. (2020). A website based on infographic for developing students' reading comprehension of economic issues. International Journal of Engineering Research \& Technology, 9(2), 434-442. https://doi.org/10.17577/ijertv9is020138

Nietfeld, J., \& Bosma, A. (2003). Examining the self-regulation of impulsive and reflective response styles on academic tasks. Journal of Research in Personality, 37(3), 118-140. https://doi.org/10.1016/s0092-6566(02)00564-0

Ozdamli, F., \& Ozdal, H. (2018). Developing an instructional design for the design of infographics and the evaluation of infographic usage in teaching based on teacher and student opinions. EURASIA Journal of Mathematics, Science and Technology Education, 14(4), 1197-1219. https://doi.org/10.29333/ejmste/81868

Peters, D. (2013). Interface design for learning: Design strategies for learning experiences. Pearson Education.

Riding, R. J., Glass, A., Butler, S. R., \& Pleydell-Pearce, C. W. (1997) Cognitive style and individual differences in EEG alpha during information processing. Educational Psychology, 17(1-2), 219-234. https://doi.org/10.1080/0144341970170117

Riding, R., \& Rayner, S. (2013). Cognitive styles and learning strategies: Understanding style differences in learning and behavior. Routledge. https://doi.org/10.4324/9781315068015

Saeed, N., Yang, Y., \& Sinnappan, S. (2009). Emerging web technologies in higher education: A case of incorporating blogs, podcasts and social bookmarks in a web programming course based on students' learning styles and technology preferences. Educational Technology and Society, 12(4), 98-109. https://drive.google.com/file/d/1WSvybBdSMQu0-wrIlKpyeGDfObluwo0J/view

Schultz, D. P., \& Schultz, S. E. (2017). Theories of personality (7th ed.). Cengage Learning.

Shafipoor, M., Sarayloo, R., \& Shafipoor, A. (2016). Infographic (information graphic): A tool for increasing the efficiency of teaching and learning processes. International Academic Journal of Innovative Research, 3(4), 39-45. https:/www.iaiest.com/datacms/articles/20191107034716pmIAJPL1510004.pdf

Shahsavar, Z., \& Hoon, T. B. (2011). Does cognitive style affect bloggers' attitude in an online learning environment? GEMA Online ${ }^{\circledR}$ Journal of Language Studies, 11(1), 159-171. http://journalarticle.ukm.my/996/

Shaltout, M., \& Fatani, H. (2017). Impact of two different infographics types "interactive static" on developing mathematical concepts among female students at second grade intermediate in the Kingdom of Saudi Arabia. International Journal of Research and Reviews in Education, 4, 1-8. https://www.researchgate.net/publication/320961540 Impact of two different infographics types interactivestatic on developing mathematical concepts among female students at second grade intermediate in the $\mathrm{K}$ ingdom of Saudi_Arabia

Siegelman, E. (1969). Reflective and impulsive observing behavior. Child Development, 40(4), 12131222. https://doi.org/10.2307/1127025

Strack, F., \& Deutsch, R. (2004). Reflective and impulsive determinants of social behavior. Personality and Social Psychology Review, 8(3), 220-247. https://doi.org/10.1207/s15327957pspr0803 1

Sudarman, S., Sugeng, S., \& Hairullah, H. (2019). Development of interactive infographic learning multimedia on study methodology study course of Economic Education Program of Mulawarman University. Jurnal Pendidikan dan Pembelajaran, 25(2), 51-

64. https://doi.org/10.17977/um047v25i12018p051 
Sweller, J. (2002). Visualisation and instructional design. Proceedings of the International Workshop on Dynamic Visualizations and Learning, Tübingen: Knowledge Media Research Center, 1501-1510. http://citeseerx.ist.psu.edu/viewdoc/summary?doi=10.1.1.325.3783

Sweller, J., Ayres, P., \& Kalyuga, S. (2011). Cognitive load theory. Springer. https://doi.org/10.1007/9781-4419-8126-4

Tayebinik, M., \& Puteh, M. (2013). The role of ambiguity tolerance in participation in online EFL courses. British Journal of Educational Technology, 44(6), E207-E208. https://doi.org/10.1111/bjet.12087

Umaru, Y. (2013). Influence of reflective and impulsive cognitive styles on students' achievement in mathematics among senior secondary school students. IFE Psychologia: An International Journal, 21(2), 123-127. https://journals.co.za/content/ifepsyc/21/2/EJC141137

Uzunboylu, H., \& Karagozlu, D. (2015). Flipped classroom: A review of recent literature. World Journal on Educational Technology. 7(2), 142-147. https://doi.org/10.18844/wjet.v7i2.46

Vanichvasin, P. (2013, 7-8 November). Enhancing the quality of learning through the use of infographics as visual communication tool and learning tool. Paper presented at The International Conference on QA Culture: Cooperation or Competition, Bangkok. http://www.onesqa.or.th/upload/download/file 652389fe995da641ccd9bc686b72df3d.pdfApage=136

Wang, C., \& Lu, H. (2018). Mediating effects of individuals' ability levels on the relationship of reflective-impulsive cognitive style and item response time in CAT. Journal of Educational Technology and Society, 21(4), 89-99. https://www.jstor.org/stable/26511540?seq=1

Wylie, R., \& Chi, M. (2014). The self-explanation principle in multimedia learning. In R. Mayer (Ed.), The Cambridge handbook of multimedia learning (pp. 413-432). Cambridge University Press. https://doi.org/10.1017/CBO9781139547369.021

Yildirim, S. (2016). Infographics for educational purposes: Their structure, properties and reader approaches. Turkish Online Journal of Educational Technology, 15(3), 98-110. https://eric.ed.gov/?id=EJ1106376

Zhu, S., Yang, H. H., MacLeod, J., Shi, Y., \& Wu, D. (2018). Parents' and students' attitudes toward tablet integration in schools. The International Review of Research in Open and Distributed Learning, 19(4), 221-241. https://doi.org/10.19173/irrodl.v19i4.2970

Corresponding author: Ensaf Nasser Al Mulhim, ealmulhim@kfu.edu.sa

Copyright: Articles published in the Australasian Journal of Educational Technology (AJET) are available under Creative Commons Attribution Non-Commercial No Derivatives Licence (CC BY-NCND 4.0). Authors retain copyright in their work and grant AJET right of first publication under CC BYNC-ND 4.0.

Please cite as: Ismaeel, D. A., \& Al Mulhim E. N. (2021). The influence of interactive and static infographics on the academic achievement of reflective and impulsive students. Australasian Journal of Educational Technology, 37(1), 147-162. https://doi.org/10.14742/ajet.6138 